\section{Bow and Arrow Brush Transects}

\section{LARRY L. WALKER}

Research Fellow, Welder Wildlife Foundation, Sinton, Texas.

\section{Highlight}

Bow-fishing equipment makes it possible for one man to rapidly establish and record line intercept brush transects.

The line intercept method of sampling vegetation (Canfield, 1941) ranks very high in accuracy (Schultz et al., 1961). Persons sampling brush, however, are often forced to employ a less desirable sampling method because a long straight line is difficult to establish in dense brush, and the efforts of two persons are required.

In a current study area, the brush canopy cover varies between 3 and 60 percent, and the brush height frequently exceeds 7 feet. The use of bowfishing equipment made it possible for an unassisted investigator to establish and record 100-foot line intercept brush transects in an average time of twenty minutes per transect.

\section{Cost of Equipment}

Bow-Solid fiberglass bows are available for under $\$ 15.00$. A bow with a pull weight of at least 45 pounds is required.

${ }^{1}$ Received August 24, 1970.

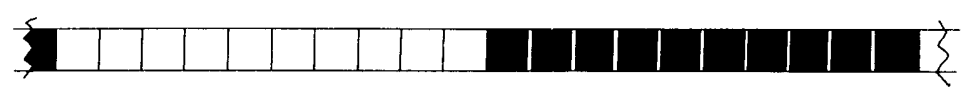

FIc. 1. A line coding which is easily read in the field. The line is marked at intervals of 1 foot, and color coded in 10-foot segments.

Bowstrings-About $\$ 1.50$ each. Spare bowstrings should be carried in the field.

Bow reel-Commercially available for about $\$ 4.00$. A homemade reel can be built from scraps.

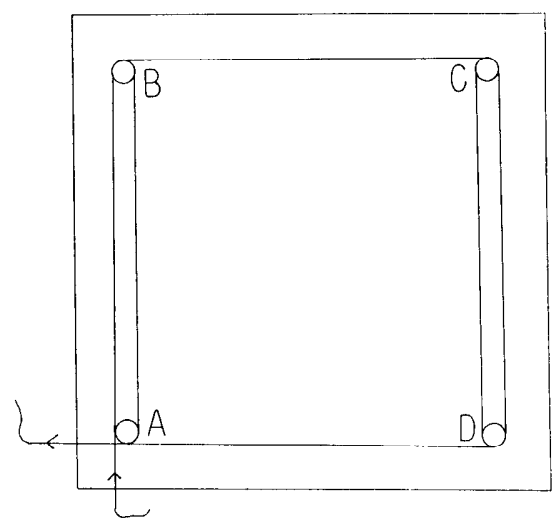

FIG. 2. Line coding jig. Points A, B, C, and $D$ are large nails driven into a board at the corners of a 1 -foot square.

Step 1. Starting at A, take $4 \frac{1}{2}$ turns around $\mathrm{AB}$, then go to $\mathrm{C}$ (equals 10 feet).

Step 2. Take $41 / 2$ turns around CD, then go to A (equals I0 feet).

Step 3. Repeat steps 1 and 2 until the desired amount of line is on the jig.

Step 4. Dye the line at points $A$ and $B$.

Step 5. Dye the line between points $C$ and $D$, and between points $D$ and $A$, leaving points $C$ and $D$ white.

Step 6. Allow the line to dry thoroughly before removing it from the jig.
Fiberglass fishing arrow-About $\$ 3.00$.

Braided nylon line (50 yds.)—About $\$ 1.35$. Ninety-four pound test squidding line is suitable.

Dye for line-Less than $\$ 1.00$. Wound dressing containing methyl violet is readily available and works well.

Miscellaneous - 2 dowels, 1 inch $\times 5 \mathrm{ft}$; 2 screwdrivers; 1 roll of plastic tape; 1 fishing snap.

Total cost-Under $\$ 30.00$.

\section{Preparation of Equipment}

Bow and reel-The reel should be taped to the handle section of the bow just below the grip.

Coded line (Figs. 1 \& 2)-The nylon line should be coded with waterproof dye and attached to the reel. A loop should be tied in the free end of the line.

Fishing arrow (Fig. 3a)-A fishing snap should be secured near the point of the arrow, and a loop of string should be attached near the nock. In use, the coded line (A) is passed through the loop (B) and attached to the snap (C). This allows easy removal of the arrow when re-winding the coded line onto the reel.

Dowels (Fig. 3b)-A notch should be cut in one end of each dowel and a point (large nail or old screwdriver blade) should be installed in the other end. 


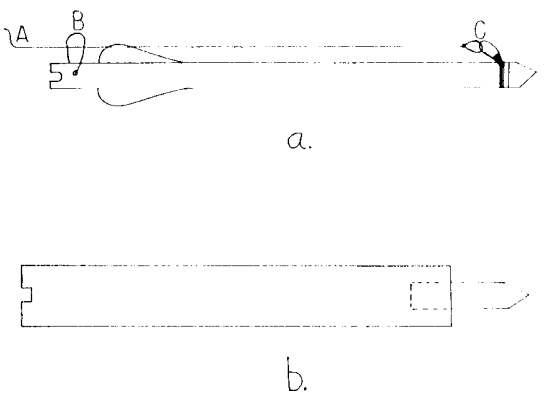

FIG. 3. Diagram of fishing arrow (a) showing coded line from the bow reel (A), string loop tied near nock (B), and fishing snap sccurcd with copper wire (C). Diagram of five-foot dowel (b) shows notch to accept transect line and installation of point.

\section{Procedure}

The investigator establishes each transect from a randomly located point in the field. An arrow, with the coded line attached, is fired downwind in a high arc. The line is staked out (Fig. 4 ), and brush intercept is read directly from the coded line. A plumb bob is recommended to insure accuracy. After the transect is recorded, the stakes are removed; the arrow is removed; and the coded line is re-wound onto the reel. With practice, the process becomes quite rapid.

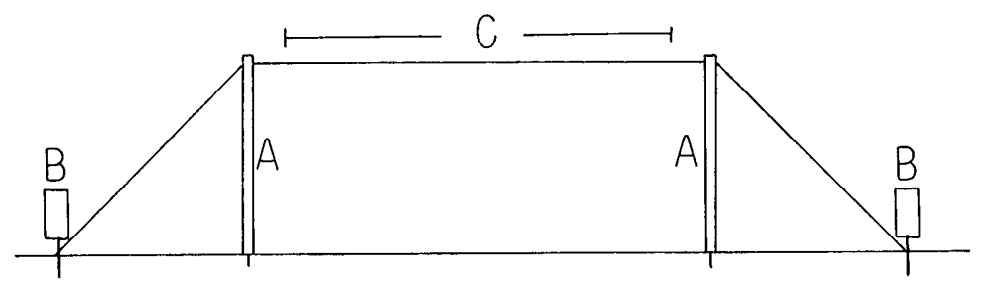

Fig. 4. Transect lay out. The bow and arrow (not shown) need not be removed when the line is staked out. A. Five-foot dowels (2), B. Screwdrivers (2), and C. Coded portion of line $(100 \mathrm{ft}$.).

\section{Precautions}

It is important that brush intercepts be recorded directly from the coded line, as braided nylon stretches considerably. Direct readings yield a true percent of intcrcept, whereas readings made with a separate measuring instrument would tend to under-estimate the percent of intercept.

All transccts should be established directly downwind to prevent bowing of the line.

\section{Comments}

A transect line 100 feet long, marked at one-foot intervals, and color coded in 10-foot segments was used in our study. The transects was staked out five feet above the ground, and a plumb bob used to aid in determining intercept. It is possible to estimate individual intercepts to within 0.5 percent with reasonable accuracy, which was considered adequate for this study. The coding, length, and height above ground of the line can easily be modified to suit the requirements of other studies.

\section{Literature Cited}

Canfield, R. H. 1941. Application of the line intercept method in sampling range vegetation. J. Forest. 39:388394.

Schultz, Arnold M., Robert P. Gibbens, and Leonard DeBano. 1961. Artificial populations for teaching and testing range techniques. J. Range Manage. 14:236-242. 